\title{
Is COVID-19 a Real Incentive for Flu Vaccination? Let the Numbers Speak for Themselves
}

\author{
Marcello Di Pumpo ${ }^{1, *}$, Giuseppe Vetrugno ${ }^{1,2}$, Domenico Pascucci ${ }^{1}$ (D) Elettra Carini ${ }^{1}$, Viria Beccia ${ }^{3}$, \\ Anna Sguera ${ }^{2}$, Maurizio Zega ${ }^{2}$, Marcello Pani ${ }^{2}$, Andrea Cambieri ${ }^{2}$, Mario Cesare Nurchis ${ }^{4}(\mathbb{D}$, \\ Floriana $D^{\prime}$ Ambrosio ${ }^{1}$, Gianfranco Damiani ${ }^{1,4}{ }^{(D)}$ and Patrizia Laurenti ${ }^{1,4}$ (D) \\ 1 Section of Hygiene, University Department of Life Sciences and Public Health, \\ Università Cattolica del Sacro Cuore, 00168 Roma, Italy; giuseppe.vetrugno@policlinicogemelli.it (G.V.); \\ domenico.pascucci@outlook.it (D.P.); elettra.carini@policlinicogemelli.it (E.C.); \\ florianadambrosio@libero.it (F.D.); gianfranco.damiani@unicatt.it (G.D.); patrizia.laurenti@unicatt.it (P.L.) \\ 2 Fondazione Policlinico Universitario A. Gemelli IRCCS, 00168 Roma, Italy; \\ anna.sguera@policlinicogemelli.it (A.S.); maurizio.zega@policlinicogemelli.it (M.Z.); \\ marcello.pani@policlinicogemelli.it (M.P.); andrea.cambieri@policlinicogemelli.it (A.C.) \\ 3 Università Cattolica del Sacro Cuore, 00168 Roma, Italy; viria.beccia@gmail.com \\ 4 Department of Woman and Child Health and Public Health-Public Health Area, Fondazione Policlinico \\ Universitario A. Gemelli IRCCS, 00168 Roma, Italy; mariocesare.nurchis@unicatt.it \\ * Correspondence: dipumpomarcello@gmail.com
}

\section{check for} updates

Citation: Di Pumpo, M.; Vetrugno, G.; Pascucci, D.; Carini, E.; Beccia, V.; Sguera, A.; Zega, M.; Pani, M.; Cambieri, A.; Nurchis, M.C.; et al. Is COVID-19 a Real Incentive for Flu Vaccination? Let the Numbers Speak for Themselves. Vaccines 2021, 9, 276. https: / / doi.org/10.3390/ vaccines 9030276

Academic Editors: Ralph A. Trip and Betsy C. Herold

Received: 22 January 2021

Accepted: 15 March 2021

Published: 18 March 2021

Publisher's Note: MDPI stays neutral with regard to jurisdictional claims in published maps and institutional affiliations.

Copyright: (c) 2021 by the authors. Licensee MDPI, Basel, Switzerland. This article is an open access article distributed under the terms and conditions of the Creative Commons Attribution (CC BY) license (https:/ / creativecommons.org/licenses/by/ $4.0 /)$.

\begin{abstract}
Seasonal flu vaccination is one of the most important strategies for preventing influenza. The attitude towards flu vaccination in light of the COVID-19 pandemic has so far been studied in the literature mostly with the help of surveys and questionnaires. Whether a person chooses to be vaccinated or not during the COVID-19 pandemic, however, speaks louder than any declaration of intention. In our teaching hospital, we registered a statistically significant increase in flu vaccination coverage across all professional categories between the 2019/2020 and the 2020/2021 campaign $(24.19 \%$ vs. $54.56 \%, p<0.0001)$. A linear regression model, based on data from four previous campaigns, predicted for the $2020 / 2021$ campaign a total flu vaccination coverage of $30.35 \%$. A coverage of $54.46 \%$ was, instead, observed, with a statistically significant difference from the predicted value $(p<0.0001)$. The COVID-19 pandemic can, therefore, be considered as ancentive that significantly and dramatically increased adherence to flu vaccination among our healthcare workers.
\end{abstract}

Keywords: flu vaccination; COVID-19; healthcare workers; adherence; vaccination coverage

Seasonal flu vaccination is one of the most important strategies for preventing influenza and reducing its healthcare, social, and economic impact [1-5]. Although influenza's disease burden varies from year to year, evidence clearly shows that vaccination can reduce flu severity and prevent hospitalizations - critical considerations at a time when the health care system is burdened by coronavirus disease 2019 (COVID-19) [6].

COVID-19, therefore, should act as a great incentive for flu vaccination.

But is it really so? The attitude towards flu vaccination in light of the COVID-19 pandemic has so far been studied in literature mostly with the help of surveys and questionnaires [7-10]. These are very useful in identifying possible causes of hesitancy and in helping to plan vaccination strategies. A study by Wang et al., for instance, analysed COVID-19 vaccination intention in relation to flu vaccine uptake and classified the reasons for refusal as "suspicion on efficacy", "effectiveness and safety", "believing it unnecessary", and "no time to take it" [7].

Whether a person chooses to be vaccinated or not during the COVID-19 pandemic, however, speaks louder than any declaration regarding his/her possible attitude towards it. A recent study analysed flu vaccine uptake in relation to COVID-19 vaccination intention and vaccine hesitancy among nurses [11]. 
We therefore proposed studying in our teaching hospital, Fondazione Policlinico Universitario “A. Gemelli” IRCCS (FPG), whether any significant increase in flu vaccination coverage occurred between last year's flu vaccination campaign and this year's campaign, marked by the COVID-19 pandemic.

As we can see from Table 1, there has been a statistically significant increase (tested with Pearson's chi-square) in flu vaccination coverage across all categories, among both healthcare and non-healthcare workers. This could mean that COVID-19 acted as an incentive to flu vaccination beyond specific health-related education.

Table 1. Vaccinated subjects by professional category campaign years and $p$-value (absolute and relative frequencies).

\begin{tabular}{cccccc}
\hline & & \multicolumn{2}{l}{$\mathbf{2 0 1 9 / 2 0 2 0}$} & \multicolumn{2}{l}{ 2020/2021 } \\
\hline Professional Category & Vaccinated & Total & Vaccinated & Total & $p$-Value \\
\hline Medical Doctors & $483(36.60 \%)$ & 1320 & $819(75.21 \%)$ & 1089 & $<0.0001$ \\
Nursing staff & $369(17.35 \%)$ & 2127 & $970(48.04 \%)$ & 2019 & $<0.0001$ \\
Other healthcare workers & $222(17.01 \%)$ & 1305 & $881(54.96 \%)$ & 1603 & $<0.0001$ \\
Medical Residents & $549(45.22 \%)$ & 1214 & $687(55.90 \%)$ & 1229 & 0.0025 \\
Total healthcare workers & $1026(24.19 \%)$ & 4241 & $2556(54.46 \%)$ & 4685 & $<0.0001$ \\
Administrative staff/ & $106(10.01 \%)$ & 1059 & $666(54.06 \%)$ & 1232 & $<0.0001$ \\
non-healthcare workers & & & & & \\
\hline
\end{tabular}

On a further note, younger generations tend to be more open to healthy lifestyles and good practices such as this [12].

Flu vaccination was offered to healthcare students across the two campaigns as well, with, respectively, 657 and 688 vaccinated students $(+4.72 \%)$. The same vaccination time slots were offered across the two campaigns, and therefore a significant increase could not be observed, however much higher the demand was.

Many efforts have been made in the past to increase adherence to this public health practice among our healthcare workers, with steady but slow results up to 2019/2020, as shown in Figure 1.

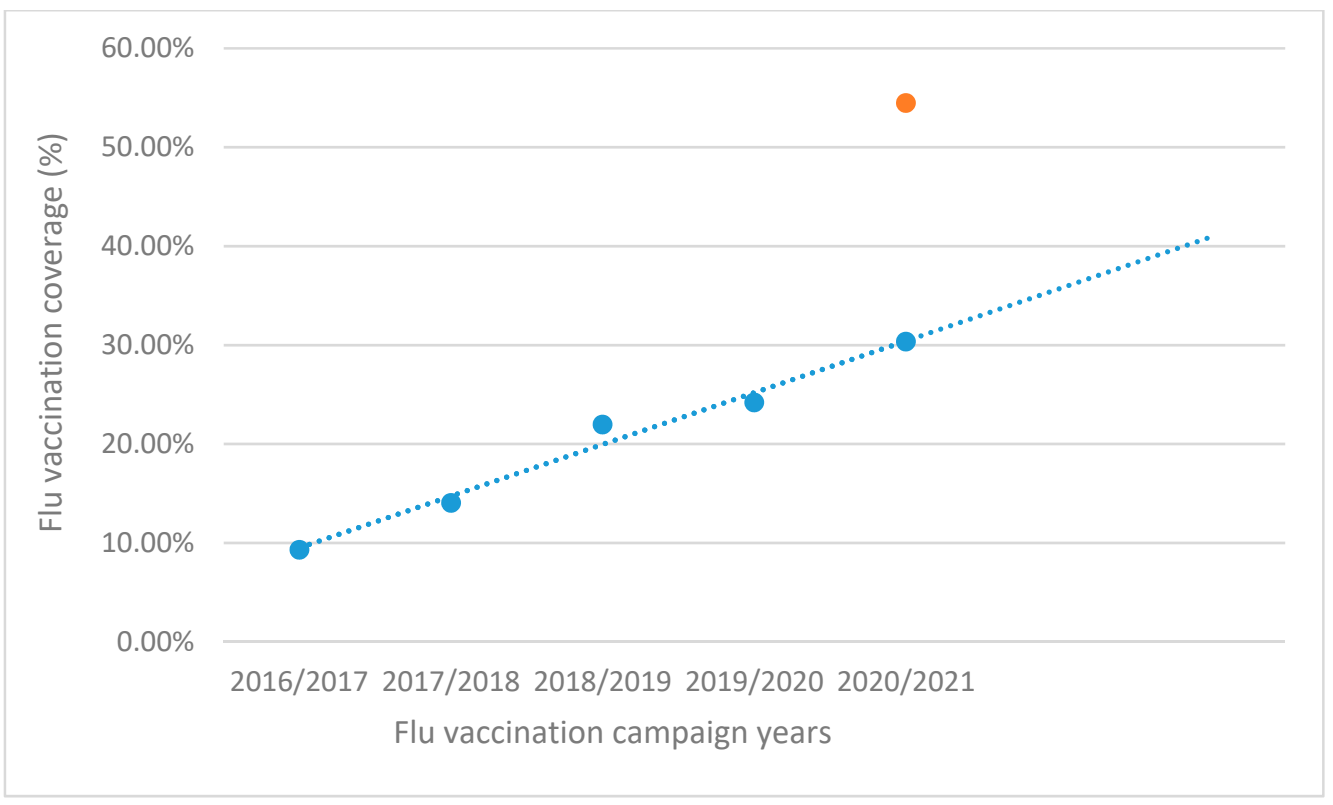

Figure 1. Flu vaccination coverage across 5 campaigns with a 4-campaign (2016/2017-2019/2020) linear regression line, 2020/2021 coverage observed (orange) vs. predicted (blue). 
Given the same conditions that had been present up to the start of the pandemic, a linear regression model, based on the data from the first 4 campaigns, predicted a total flu vaccination coverage of $30.35 \%$ (blue in Figure 1). A significant departure from the observed $54.46 \%$ coverage (orange in Figure 1 ) was found $(p<0.0001$ ).

Although the analysis was performed without taking into account other possible confounders, the COVID-19 pandemic has been a major difference factor between 2020/2021 campaign and all other ones. It can, therefore, be regarded as an incentive that significantly and dramatically increased adherence to a good public health practice such as flu vaccination among our healthcare workers.

In conclusion, we hope that these results are indicative of a disposition towards future COVID-19 vaccination as well, as shown by other studies [11], even considering all the possible limitations connected to the analogy between this vaccine and the flu vaccine.

Let the numbers speak for themselves.

Author Contributions: Conceptualization and Project administration, P.L., G.D.; Investigation, M.D.P., D.P., E.C., V.B., M.C.N., F.D.; Methodology, M.D.P.; Writing-original draft, M.D.P.; Writingreview and editing, M.D.P., M.C.N.; Visualization, M.D.P.; Software, M.D.P.; Data curation, E.C., D.P., V.B., M.C.N., F.D., M.D.P.; Formal analysis, M.D.P.; Resources: G.V., P.L., A.C., M.P., M.Z., A.S.; Validation, G.D., P.L.; Supervision, A.S., G.V., A.C., M.Z., M.P., G.D., P.L. All authors have read and agreed to the published version of the manuscript.

Funding: This research received no external funding.

Institutional Review Board Statement: The study was approved by the Ethics Committee (Prot. $\mathrm{n}$. 2275/21.; ID 3706) of the Policlinico Universitario A. Gemelli IRCCS and by the Internal Board of Università Cattolica del Sacro Cuore.

Informed Consent Statement: Informed consent was obtained from all subjects involved in the study.

Data Availability Statement: Data presented in this study are available upon request from the corresponding author.

Conflicts of Interest: The authors declare no conflict of interest.

\section{References}

1. Barbara, A.; La Milia, D.I.; Di Pumpo, M.; Tognetto, A.; Tamburrano, A.; Vallone, D.; Viora, C.; Cavalieri, S.; Cambieri, A.; Moscato, U.; et al. Strategies to Increase Flu Vaccination Coverage among Healthcare Workers: A 4 Years Study in a Large Italian Teaching Hospital. Vaccines 2020, 8, 85. [CrossRef] [PubMed]

2. Rittle, C. Can Increasing Adult Vaccination Rates Reduce Lost Time and Increase Productivity? Work. Heal. Saf. 2014, 62, 508-515. [CrossRef] [PubMed]

3. Osterholm, M.T.; Kelley, N.S.; Sommer, A.; Belongia, E.A. Efficacy and Effectiveness of Influenza Vaccines: A Systematic Review and Meta-Analysis. Lancet Infect. Dis. 2012, 12, 36-44. [CrossRef]

4. Gianino, M.M.; Politano, G.; Scarmozzino, A.; Charrier, L.; Testa, M.; Giacomelli, S.; Benso, A.; Zotti, C.M. Estimation of Sickness Absenteeism among Italian Healthcare Workers during Seasonal Influenza Epidemics. PLoS ONE 2017, 12, e0182510. [CrossRef] [PubMed]

5. Corson, S.; Robertson, C.; Reynolds, A.; McMenamin, J. Modelling the Population Effectiveness of the National Seasonal Influenza Vaccination Programme in Scotland: The Impact of Targeting All Individuals Aged 65 Years and Over. Influenza Other Respi. Viruses 2019, 13, 354-363. [CrossRef] [PubMed]

6. Jaklevic, M.C. Flu Vaccination Urged during COVID-19 Pandemic. JAMA J. Am. Med. Assoc. 2020, 324. [CrossRef]

7. Wang, K.; Wong, E.L.Y.; Ho, K.F.; Cheung, A.W.L.; Chan, E.Y.Y.; Yeoh, E.K.; Wong, S.Y.S. Intention of Nurses to Accept Coronavirus Disease 2019 Vaccination and Change of Intention to Accept Seasonal Influenza Vaccination during the Coronavirus Disease 2019 Pandemic: A Cross-Sectional Survey. Vaccine 2020, 38, 7049-7056. [CrossRef]

8. Pastorino, R.; Villani, L.; Mariani, M.; Ricciardi, W.; Graffigna, G.; Boccia, S. Impact of COVID-19 Pandemic on Flu and COVID-19 Vaccination Intentions among University Students. Vaccines 2021, 9, 70. [CrossRef] [PubMed]

9. Domnich, A.; Cambiaggi, M.; Vasco, A.; Maraniello, L.; Ansaldi, F.; Baldo, V.; Bonanni, P.; Calabrò, G.E.; Costantino, C.; de Waure, C.; et al. Attitudes and Beliefs on Influenza Vaccination during the Covid-19 Pandemic: Results from a Representative Italian Survey. Vaccines 2020, 8, 711. [CrossRef] [PubMed] 
10. Sokol, R.L.; Grummon, A.H. COVID-19 and Parent Intention to Vaccinate Their Children against Influenza. Pediatrics 2020, 146. [CrossRef] [PubMed]

11. Kwok, K.O.; Li, K.K.; Wei, W.I.; Tang, A.; Wong, S.Y.S.; Lee, S.S. Influenza Vaccine Uptake, COVID-19 Vaccination Intention and Vaccine Hesitancy among Nurses: A Survey. Int. J. Nurs. Stud. 2021, 114, 103854. [CrossRef]

12. Lehmann, B.A.; Ruiter, R.A.C.; Wicker, S.; Chapman, G.; Kok, G. Medical Students' Attitude towards Influenza Vaccination. BMC Infect. Dis. 2015, 15, 1-7. [CrossRef] [PubMed] 